\title{
Modeling and Calculation of Water Intake of Siberia
}

\author{
Anatoly I. Matiushenko*, \\ Gregory V. Krasavin and Viktor K. Viter \\ Siberian Federal University \\ 79 Svobodny, Krasnoyarsk, 660041, Russia
}

Received 03.12.2016, received in revised form 27.01.2017, accepted 02.02.2017

The article deals with certain subterranean and surface water inlet springs' designing particularities applying to Siberia. It is shown that the roughness coefficient for the cost is inversely proportional to that small fillings channel correspond to large values of it, and vice versa. The results allowed us to develop methods for the design of intake structures at the complexity, without involving costly results of field measurements.

Keywords: designing and calculation of water intakes, coefficient of roughness, surface and underground sources.

Citation: Matiushenko A.I., Krasavin G.V., Viter V.K. Modeling and calculation of water intake of Siberia, J. Sib. Fed. Univ. Eng. technol., 2017, 10(3), 407-413. DOI: 10.17516/1999-494X-2017-10-3-407-413.

\section{Моделирование}

\section{и расчет водозаборов Сибири}

\author{
А.И. Матюшенко, Г.В. Красавин, В.К. Витер \\ Сибирский федеральный университет \\ Россия, 660041, Красноярск, пр. Свободный, 79
}

\begin{abstract}
Изложены некоторые особенности проектирования водозаборных сооружений в Сибири из подземных и поверхностных источников. Показано, что для коэффициента шероховатости связь с расходом обратно пропорииональна, когда мальм наполнениям русла соответствуют большие значения его и наоборот. Полученные результаты позволили разработать методы проектирования водозаборных сооружений меньшей трудоемкости, без привлечения результатов дорогостоящих натурных измерений.

Ключевые слова: проектирование и расчет водозаборов, коэффициент шероховатости, подземные и поверхностные источники.
\end{abstract}

(C) Siberian Federal University. All rights reserved

* Corresponding author E-mail address: matyshenko@icoud.com 
Проектированию и расчету водозаборов предшествует комплекс гидрологических изысканий, связанных с выбором устойчивого створа реки-водоисточника [1]. По данным изысканий определяют элементы гидравлики потока и морфометрии русла, например связь относительной ширины и формы сечения по расходу, другие гидравлико-гидрологические зависимости.

Выполненные в Сибирском федеральном университете исследования показали, что для коэффициента шероховатости связь с расходом, как правило, обратно пропорциональна, когда малым наполнениям русла соответствуют большие значения его и наоборот. Коэффициент Шези изменяется асинхронно коэффициенту шероховатости, имея тенденцию к стабилизации своего значения на средних и высоких горизонтах. Коэффициент гидравлического сопротивления или трения по Дарси ведет себя при повышении расхода подобно изменению коэффициента шероховатости, т.е. вначале на малых глубинах резко убывает, а затем на средних и больших уровнях плавно уменьшается. Для многих потоков зафиксированы величины расходов и относительной ширины, когда гидравлическое сопротивление минимально [2]. Объясняется это тем, что с ростом расхода убывающее на средних и вышесредних горизонтах сопротивление возрастает из-за того, что поток (до выхода на пойму) начинает затапливать свои русловые макро- и мезоформы - косы, побочни, осередки, другие неровности дна и берегов, не задействованные во время межени, хотя относительная ширина при этом продолжает монотонно убывать до самого пика гидрографа. Поэтому две функции, гидравлическое сопротивление и относительная ширина в зависимости от расхода равнонаправлены, а их связь между собой при разработанной потоком форме сечения имеет минимум. Имея прямую пропорциональность с расходом, гидравлический уклон, принимаемый по уклону свободной поверхности как для равномерного режима, при больших наполнениях русла начинает стабилизироваться. Его связь со средней скоростью или со скоростным напором имеет параболический характер и подлежит дальнейшему исследованию и обобщению для разных типов русел разной водности. С коэффициентом шероховатости и относительной шириной гидравлический уклон связан в обратной пропорции, и это станет понятным, если учесть, что, например, большим уклонам соответствуют и большие расходы, а большим расходам сопутствуют малые величины коэффициента шероховатости. При увеличении относительной ширины уклон снижается - на малых расходах потери капора у потока также невелики, когда он с минимальной затратой энергии течет в широком русле с большой относительной шириной. Поскольку связи расхода - с уклоном с одной стороны и расхода с относительной шириной и формой русла с другой, на графиках этих характеристик разнонаправлены, то обратная пропорциональность между уклоном и относительной шириной фиксирует то обстоятельство, что меженные потоки с малыми уклонами имеют и широкие (т.е. с большой относительной шириной) русла. Мутность от взвешенных наносов, включая ее наибольшую концентрацию во время паводков (порядка, например, 1000 г/м³), на изменение гидравлического сопротивления, оцениваемого коэффициентом трения по Дарси, практически не влияет [1].

В рамках оборотных систем водоснабжения необходимо решать вопросы подпитки систем водой. В этой связи достаточно актуальна разработка надежного узла водозабора. Предложенные конструкции отвечают ряду новых требований по рыбозащите, но при этом не имеют дви- 
жущихся узлов или узлов, подверженных засорению и требующих периодической промывки (сетки, фильтрующий материал и т.д.). Водоприемник для неглубоких водоемов представляет собой вихревую камеру щелевого типа с рыбоотгораживающим коробом. Забор воды производится из нижних слоев воды, при этом не затрагиваются верхние и средний слои воды, где наблюдается максимальная концентрация молоди рыб. Водоприемник имеет небольшие размеры по высоте, что позволяет использовать его в неглубоких водоемах. Вторая конструкция представляет собой модификацию водозабора фуникулерного типа. На платформе установлено зонтичное рыбозащитное устройство круглой или прямоугольной в плане формы. Напорные трубы могут перемещаться по направляющим вместе с платформой. Положительной стороной в предложенной конструкции является работа её весь сезон в одном положении и относительно низкая стоимость. Для обеспечения работы конструкции в одном положении необходимо обеспечить её установку под минимальный уровень воды в водоёме.

Бурный рост развития производственных сил Восточной Сибири требует решение задачи по интенсификации систем водоснабжения и повышению их производительности. Одной из эффективных систем водоснабжения, позволяющих получать (питьевую) воду без применения сложных в строительстве и дорогостоящих в эксплуатации очистных сооружений, признаны инфильтрационные водозаборы $[4,7,8]$. Особенностью эксплуатации инфильтрационные водозаборов является снижение во времени их дебита вследствие кольматации руслового аллювия в зоне активного влияния сооружений. Наиболее точный расчет производительности данного вида сооружений может быть получен только за счет привлечения двух- или трехмерной постановки задачи о процессах кольматации с учетом начальных и граничных условий [1]. Система нелинейных уравнений, описывающая этот процесс, при гидрогеологических расчетах подрусловых инфильтрационных водозаборов в случае двухмерной задачи имеет следующий вид:

1) уравнение движения (гидродинамического давления):

$$
\frac{\partial}{\partial x}\left(\gamma \frac{\partial H}{\partial x}\right)+\frac{\partial}{\partial y}\left(\gamma \frac{\partial H}{\partial y}\right)=0
$$

где $\gamma=\frac{K}{\mu(1-\rho)} ; K-$ коэффициенты проницаемости; $\mu-$ коэффициент динамической вязкости; $\rho$ - концентрация взвешенных наносов; $H$ - гидродинамический напор;

2) уравнение неразрывности (конвективного массопереноса):

$$
(1-\zeta) \frac{\partial \rho}{\partial \tau}+\frac{1}{m_{0}(1-\rho)}\left[q_{x} \frac{\partial \rho}{\partial x}+q_{y} \frac{\partial \rho}{\partial y}\right]=-(1-\varepsilon-\rho) \frac{\partial \zeta}{\partial \tau},
$$

где $m_{0}$ - начальная пористость руслового аллювия; $q_{x} q_{y}$ - удельный расход соответственно по направлениям $(x)$ и $(y) ; \zeta$ - насыщенность руслового аллювия взвешенными наносами в процессе кольматации; $\varepsilon$ - пористость осевшей массы наносов; $\tau$ - время;

3) уравнение кинетики процесса кольматации (массообмена) [9]:

$$
\frac{\partial \zeta}{\partial \tau}=F(\rho, \zeta)
$$




$$
F(\rho, \zeta)=\lambda\left(\rho-\frac{a_{0} \zeta}{\zeta_{0}-\zeta}\right)
$$

где $\zeta_{0}$ - максимальная (предельная) насыщенность; $\lambda, \alpha_{0}, \zeta$ - постоянные коэффициенты.

Начальные и граничные условия системы могут быть:

$$
\begin{aligned}
& H(0, \tau)=0, \quad H(h, \tau)=H_{1}(\tau) ; \\
& \rho(x, 0)=\left\{\begin{array}{l}
0, x>0 \\
\rho_{0}(0) ; x=0
\end{array} ;\right. \\
& \rho(0, \tau)=\rho(\tau) \\
& \zeta(x, 0)=0
\end{aligned}
$$

при

$$
q=-\frac{K}{\mu} \cdot q r a d H
$$

Теоретически и экспериментально-натурным подтверждением выявлено приближенное постоянство фактических и фиктивных расходов $(K-$ фиктивный расход - произведение ширины потока $B$ на максимальную глубину в сечении $H$ и наибольшую поверхностную скорость v), имеющее ряд практических приложений.

Определение расхода по наиболее доступным для измерения элементам его фиктивного значения $Q=K B H V$ требует минимальной натурной информации, т.е. не нужно определение измерения площади живого сечения, наибольшую поверхностную скорость измеряют поплавками, а графические действия аппроксимируют линейной функцией.

Интер- и экстраполировать расход в основном русле, на пойме и в каньонном створе с вертикальными берегами необходимо в последних двух случаях при изломе связи расхода с его фиктивным значением. Так, для пойм линейный график связи фактических (ордината) и фиктивных (абсцисса) расходов имеет излом по абсциссе. Для малоизученных или совсем неизученных потоков наиболее простым способом экстраполяции здесь является метод аналогий, где за основу принимается движение в пойменном створе с приблизительно одинаковыми природными условиями. Для р. Каса (Большого Каса) и Малого Каса в междуречье Оби и Енисея, например, угол излома связи фактических и фиктивных расходов на соответствующих графиках приблизительно равен $20^{\circ} \mathrm{C}[3,8]$. Рассмотрим это постоянство как константу гидравлического подобия при натурном моделировании открытых потоков, например канала, отводимого от реки-источника. Гидравлическое подобие при натурном моделировании будет соблюдено, если $K$ для естественного аналога (реки) и нового искусственного потока (канала) имеет одинаковую величину. Коэффициент формы русла при этом для канала должен быть равен таковому для аналога при расходе последнего, равном для канала. Аналог подразумевается с устойчивыми формами русла, источником информации служат натурные данные Гидрологических ежегодников по бассейнам, где пройдет трасса канала.

Международный стандарт по измерению расхода в открытых потоках методами исследования поля скоростей ИСО 748-73 основой для измерения считает произведение скорости на 
площадь, т.е. $Q=\Sigma U \Delta \omega$, где $U$ - произвольная точечная скорость на элементарной площадке $\Delta \omega$ живого сечения $\omega$.

Учитывая это, можно представить следующие варианты приближенного определения расхода, включая известные зависимости с коэффициентами $K_{1}$ и $K_{2}$, отношениями средней скорости по сечению (v) к средней скорости на поверхности $\left(v_{\text {пов }}\right)$ и средней по сечению к наибольшей по поверхности $(V)$ и где $B H$ - фиктивная площадь сечения (в м²), $B V$ - величина с размерностью удельного расхода $h v=Q / B$ в м $^{2} / \mathrm{c}$ и $H V$ - величина, пропорциональная удельному расходу:

$$
Q=\left\{\begin{array}{ll}
K_{1} \omega v_{\text {noв }}, & K_{1}=v / v_{\text {пов }} \\
K_{2} \omega V, & K_{2}=v / V \\
K_{3} B H V, & K_{3}=Q / B H V \\
K_{4} B H, & K_{4}=Q / B H \\
K_{5} B H, & K_{5}=Q / B V \\
K_{6} H V, & K_{6}=Q / H V
\end{array} .\right.
$$

Числовые значения размерных коэффициентов в этих формулах подлежат определению для конкретных типовых случаев рек и ручьев. Так, для верхних плесов Енисея и его протоков с галечно-гравелистым и малоразмываемым руслом $K_{4}=1,50 \mathrm{м} / \mathrm{c}, K_{5}=4,0$ м, $K_{6}=16,7$ м. Последние три зависимости по определению расхода удобно распространять на правильные русла до выхода потока на пойму. Погрешность вычислений

$$
\Delta Q=\left\{\begin{array}{l}
\left(\frac{Q_{\text {еж }}-Q_{\bar{k}}}{Q_{\text {еж }}}\right) \cdot 100 \% \\
\left(1-\frac{Q_{\bar{k}}}{Q_{\text {еж }}}\right) \cdot 100 \%
\end{array} ;\right.
$$

где $Q_{\text {еж }}$ - расходы, приводимые в Гидрологических ежегодниках и принимаемые за контрольные величины; $Q_{\bar{k}}$ - расходы, вычисленные по предлагаемым здесь формулам при среднеарифметических значениях коэффициентов $K$ с индексами $3,4,5$ и 6.

Рост водопотребления и развитие промышленности в Красноярском крае потребовали решения проблемы отыскания рациональных способов забора воды из поверхностных источников. В этой связи актуальна задача совершенствования известных решений и разработка принципиально новых конструкций водоприемников для условий шугоносных сибирских рек. Одним из методов повышения надежности, в частности борьбы шуголедовыми осложнениями, а также обеспечение надежной рыбозащиты является снижение малых скоростей на входе в водоприемнике, вплоть до 0,1-0,05 м/с. Необходимо и создание равномерности распределения удельных расходов вдоль развитого водоприемного фронта в режимах забора и промывки обратным током. Это ставит вопрос о целесообразности применения на реках Сибири водоприемников с различными вихревыми камерами и водоприемными отверстиями, оборудованными фильтрующими рыбозащитными устройствами как удовлетворяющих этим требованиям [10]. Действующие типовые проекты пока ограничены производительностью водозабора $1,5 \mathrm{~m}^{3} / \mathrm{c}$ на одну самотечную трубу, а суммарная длина водоприемника при этом достигает 5065 м, что не всегда приемлемо для местных условий водоема. 
Известны оголовки с увеличенной площадью водоприема при малых габаритах водозабо$\mathrm{pa}$, что дает возможность использования новых решений при реконструкции. Отличие разработанных конструкций от известных заключается, главным образом, в конфигурации входных устройств, которым придается объемная сегментная форма. Съемные фильтрующие кассеты, выдвинутые в поток цилиндрической или колоидальной поверхностью, устанавливаемой вдоль или поперек направления потека, позволяют увеличить площадь водоприемных окон до 2-2,5 раз. Предлагаемые водоприемники с открытыми вихревыми камерами, с сегментными фильтрами на входе (заполнение керамзитобетоном, тополимербетоном) имеют достаточно широкие пределы применения и допускают различные конструктивные исполнения для любых гидрологических условий, диапазонов производительностей. Забор воды из рек с недостаточными глубинами с малыми скоростями течения в меженный период года, в т.ч. водоемов $(v \leq 0,1 \mathrm{~m} / \mathrm{c}$, $H=3-4$ м), осуществляется объемными фильтрами с цилиндрической поверхностью, ограниченной сверху и снизу сегментными козырьками, позволяющими селективно отбирать воду из средних слоев потока. При увеличенных скоростях $0,1<v<0,40,1 \mathrm{~m} / \mathrm{c}$, во избежание появления зон повышенного давления с верховой по течению стороны выпуклых в поток кассет, регулирование распределения удельных расходов бокового притока осуществляется переменной степенью выпуклости кассет по длине камеры. Следует отметить, что более равномерно втекание достигается поворотом водоприемной грани к направлению транзитного течения $\left(\gamma \div 15^{\circ}\right)$, при этом предпочтителен односторонний забор, не «реагирующий» в отличие от двухстороннего на несимметричное обтекание. Для обеспечения надежной эксплуатации при наличии поверхностной шуги входные устройства целесообразнее выполнять с коноидальной водопроницаемой поверхностью, скошенной под острым углом к потоку и ограниченной сверху козырьком. Для более полного использования фильтрующей поверхности рекомендуется блок кассет, устанавливаемый вдоль потока по всей длине камеры, разделенной на отдельные панели ребрами жесткости. Конструкция с двухсторонним забором воды обеспечивает равномерность втекания по длине фронта практически при любых скоростных режимах, но требует более значительных глубин, строгой ориентации водоприемной грани в потоке, а также нашивки клинообразного элемента при $v>0,15$ м/с со стороны верхового бокового козырька.

Результаты детальных лабораторных исследований предлагаемых конструкций используются при разработке типового проекта «Затопленные водоприемники с рыбозащитными устройствами производительностью 1-3 м³/с». Рекомендации по проектированию и расчету вихревых водозаборных камер увеличенной производительности использованы в проекте реконструкции внеплощадочного водоснабжения Ирша-Бородинского угольного разреза в Красноярском крае.

Таким образом, проведенное исследование позволило разработать метод проектирования водозаборных сооружений меньшей трудоемкости без привлечения результатов дорогостоящих натурных измерений.

\section{Список литературы}

[1] Турутин Б.Ф. Проектирование и расчет водозаборных сооружений из подземных источников; ред. В.А. Кулагин, В.М. Журавлев. Красноярск: ИПЦ КГТУ, 2004. 223 с. [Turutin B.F. Design and calculation of water intake facilities from underground sources; Ed. V.A. Kulagin, V.M. Zhuravlev. Krasnoyarsk, CPI KSTU, 2004. 223 p. (in Russian)]. 
[2] Матюшенко А.И., Турутин Б.Ф. Водозаборы подземных вод; ред. В.А. Кулагин, В.М. Журавлев. Красноярск: ИПЦ КГТУ, 2005. 248 с. [Matiushenko A.I., Turutin B.F. Water intakes of underground water; Ed. V.A. Kulagin, V.M. Zhuravlev. Krasnoyarsk, CPI KSTU, 2005. 248 p. (in Russian)].

[3] Матюшенко А.И., Турутин Б.Ф., Лютов А.В. Комплексное использование водных ресурсов (Восточно-Сибирские регионы); ред. Б.Ф. Турутина. Красноярск: ИПЦ КГТУ, 2003. 300 с. [Matiushenko A.I. Turutin B.F., Liutov A.V. Integrated water resources management (East Siberia); Ed. B.F. Turutin. Krasnoyarsk, CPI KSTU, 2003. 300 p. (in Russian)].

[4] Турутин Б.Ф. Матюшенко А.И., Кулагин В.А. Инженерно-экологическая надежность водоснабжения из подземных источников. Красноярск: ИПЦ КГТУ, РИО КрасГАСА, 2006. 208 c. [Turutin B.F., Matiushenko A.I., Kulagin V.A. Engineering and environmental reliability of the water supply from underground sources. Krasnoyarsk, CPI KSTU, RIO KrasGASA, 2006. 208 p. (in Russian)].

[5] Матюшенко А.И., Турутин Б.Ф., Кулагин В.А. Водоснабжение и водопотребление г. Красноярска. Красноярск: ИПЦ КГТУ, 2006. 329 с. [Matiushenko A.I., Turutin B.F., Kulagin V.A. Water supply and water consumption of Krasnoyarsk. Krasnoyarsk, CPI KSTU, 2006. 329 p. (in Russian)].

[6] Кулагин В.А., Кулагина Т.А., Матюшенко А.И., Турутин Б.Ф. Физика атмосферы и гидрофизика. Красноярск: ИПЦ КГТУ, 2006. 498 с. [Kulagin V.A., Kulagina T.A., Matiushenko A.I., Turutin B.F. Physics of atmosphere and hydrophysics. Krasnoyarsk, CPI KSTU, 2006. 498 p. (in Russian)].

[7] Турутин Б.Ф., Матюшенко А.И. Термика инфильтрационных сооружений. Красноярск: ИПЦ КГТУ, 2002. 208 c. [Turutin B.F., Matiushenko A.I. Buoyant thermal of infiltration facilities. Krasnoyarsk, CPI KSTU, 2002. 208 p. (in Russian)].

[8] Кулагин В.А., Крючков Г.П. Инженерно-экологическая особенность проектирования водозаборных сооружений Сибирских регионов. Экология урбанизированных территорий, 2007, 3, 65-68. [Kulagin V.A., Kryuchkov G.P. Engineering and environmental feature of the design of water intake facilities of the Siberian region. Ecology of the urbanized territories, 2007, 3, 65-68 (in Russian)].

[9] Матюшенко А.И., Лютов А.В., Кулагин В.А., Турутин Б.Ф. Теплофизика систем водоснабжения. Красноярск: ИПЦ КГТУ, 2002. 224 с. [Matiushenko A.I. Liutov A.V. Kulagin V.A. Turutin B.F. Thermal physics of water supply systems. Krasnoyarsk: CPI KSTU, 2002. 224 p. (in Russian)].

[10] Кулагин В.А., Крючков Г.П. Природные особенности исследования водозаборов Сибири из подземных источников. Экология урбанизированных территорий, 2007, 3, 52-54. [Kulagin V.A., Kryuchkov G.P. The natural features of studies of Siberia intake from underground sources. Ecology of the urbanized territories, 2007, 3, 52-54 (in Russian)]. 